\title{
Experimental and Numerical Investigations of Hypervelocity Carbon Dioxide Flow over Blunt Bodies
}

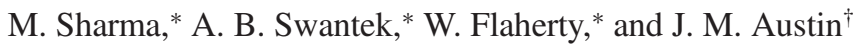 \\ University of Illinois at Urbana-Champaign, Urbana, Illinois 61801 \\ and \\ S. Doraiswamy \\ University of Minnesota, Minneapolis, Minnesota 55455
}

\section{DOI: $10.2514 / 1.49386$}

\begin{abstract}
This paper represents ongoing efforts to study high-enthalpy carbon dioxide flows in anticipation of the upcoming Mars Science Laboratory and future missions. The work is motivated by observed anomalies between experimental and numerical studies in hypervelocity impulse facilities. In this study, experiments are conducted in the hypervelocity expansion tube that, by virtue of its flow acceleration process, exhibits minimal freestream dissociation in comparison with reflected shock tunnels, simplifying comparison with simulations. Shock shapes of the laboratory aeroshell at angles of attack of 0,11 , and $16 \mathrm{deg}$ and spherical geometries are in very good agreement with simulations incorporating detailed thermochemical modeling. Laboratory shock shapes at a 0 deg of attack are also in good agreement with data from the LENS $X$ expansion tunnel facility, confirming results are facility-independent for the same type of flow acceleration. The shock standoff distance is sensitive to the thermochemical state and is used as an experimental measurable for comparison with simulations and two different theoretical models. For low-density small-scale experiments, it is seen that models based upon assumptions of large binary scaling values do not match the experimental and numerical results. In an effort to address surface chemistry issues arising in high-enthalpy groundtest experiments, spherical stagnation point and aeroshell heat transfer distributions are also compared with the simulation. Heat transfer distributions over the aeroshell at the three angles of attack are in reasonable agreement with simulations, and the data fall within the noncatalytic and supercatalytic solutions.
\end{abstract}

\section{Introduction}

I N HIGH-ENTHALPY hypersonic flight, thermochemical relaxation times are typically comparable to flow residence times, leading to nonlinear coupling between chemical reaction, vibrational excitation, and fluid mechanics. In carbon dioxide flows that are relevant to Martian planetary entry, thermochemical effects are particularly significant and may be potentially responsible for some recent anomalous results in blunt body shock layers. The hypersonic facilities at the Calspan University of Buffalo Research Center (CUBRC) have been central to the investigation of planetary entry flight conditions for many programs, including the upcoming Mars Science Laboratory (MSL) mission targeting exploration of the Martian surface. Recent studies revealed that the experimentally observed shock shape and standoff distance differed significantly from numerical simulations over a 24-in.-diam MSL model for highenthalpy test conditions at 5 and $10 \mathrm{MJ} / \mathrm{kg}$ in the Large Energy National Shock Tunnel (LENS) I reflected shock-tunnel facility [1]. The computed shock standoff distance for the $5 \mathrm{MJ} / \mathrm{kg}$ test condition was a factor of 2.25 times smaller than the experimental value. However, at a $2 \mathrm{MJ} / \mathrm{kg}$ test condition in the same facility, no such differences were observed. To examine this discrepancy further, the same model was tested in the LENS $\mathrm{X}$ expansion tube facility at

Received 15 February 2010; revision received 6 June 2010; accepted for publication 8 June 2010. Copyright (C) 2010 by University of Illinois. Published by the American Institute of Aeronautics and Astronautics, Inc., with permission. Copies of this paper may be made for personal or internal use, on condition that the copier pay the $\$ 10.00$ per-copy fee to the Copyright Clearance Center, Inc., 222 Rosewood Drive, Danvers, MA 01923; include the code 0887-8722/10 and $\$ 10.00$ in correspondence with the CCC.

${ }^{*}$ Graduate Student, Department of Aerospace Engineering. Member AIAA.

Assistant Professor, Department of Aerospace Engineering. Senior Member AIAA.

†Post-Doctoral Fellow, Aerospace Engineering and Mechanics. Member AIAA

${ }^{\S}$ Professor, Aerospace Engineering and Mechanics. Fellow AIAA.
$5 \mathrm{MJ} / \mathrm{kg}$ [1]. Excellent agreement was obtained between simulations and experiments in the LENS $\mathrm{X}$ facility.

It was proposed that a possible cause for the observed reflected shock-tunnel discrepancy was due to uncertainty in the thermochemical state of the freestream after the thermally excited and chemically dissociated test gas was strongly expanded in the nozzle. A follow-up numerical study found that shock shape and standoff distance matched experimental observation when $42 \%$ of the total energy was frozen in vibration [2]. As discussed by the authors, such a result is clearly aphysical, and especially so when one considers that the original calculation had $3.6 \%$ of the total energy frozen in vibration. Additionally, frozen vibrational energy was seen to have a greater impact upon the shock standoff distance than frozen chemical energy. As mentioned previously, for a very similar run condition, such a discrepancy was not observed in an expansion tunnel facility. This suggests that complex $\mathrm{CO}_{2}$ system vibrational relaxation processes, such as those occurring in the reflected shock-tunnel nozzle, may not be completely understood.

Several researchers have also studied high-enthalpy $\mathrm{CO}_{2}$ flow over blunt bodies. Stewart and Chen measured bow shock standoff distances over a $140 \mathrm{deg}$ blunt angle cone (an early version of the MSL model) for a $14.3 \mathrm{MJ} / \mathrm{kg}$ pure $\mathrm{CO}_{2}$ run condition in the NASA Ames 42 in. shock tunnel [3]. Of the three different gases investigated (air, pure $\mathrm{CO}_{2}$, and a $\mathrm{CO}_{2}$-Ar mixture) for the same blunt body, the maximum discrepancy between the computation and the experiment in the shock standoff distance was observed for the pure $\mathrm{CO}_{2}$ condition. Despite the similarity between the NASA Ames highenthalpy reflected shock-tunnel test conditions and those at the LENS facility, the differences between the numerical and experimental results were much less pronounced in the Ames facility than observed at the CUBRC.

In the T5 facility, Wen and Hornung compared nonequilibrium theoretical sphere shock standoff distance predictions for $\mathrm{CO}_{2}$ (and also nitrogen) with extensive experimental and numerical results and found acceptable agreement [4]. In the reflected shock-tunnel High Enthalpy Shock Tunnel Göttingen, $\mathrm{CO}_{2}$ flow over a 70 deg blunt cone was studied using simulations and experiments by Netterfield et al. [5]. 
Hollis and Perkins compared various sphere-cone model forebody and aftbody heat transfer values with computational simulations in the NASA Hypersonic Pulse facility expansion tube [6,7] and the 31 in. Mach 10 Langley wind tunnel [6]. Overall, very good agreement between the simulation and the experiment was achieved. The previously discussed CUBRC experiments formed a component of the very comprehensive investigation of high-enthalpy $\mathrm{CO}_{2}$ spherecone blunt body flowfields, incorporating several facilities and extensive numerical modeling. In the California Institute of Technology T5 facility, a series of shots for a 70 deg blunt cone were conducted, and surface heat flux measurements were obtained. At the angle of attack, it was observed that supercatalytic simulations agreed best with laminar windside data, whereas the turbulent leeside was most accurately predicted by the noncatalytic cases []․ Similar results were also observed for LENS experiments when the model was initially coated in $\mathrm{SiO}_{2}$ to promote a noncatalytic response [9]. In LENS I, at a 0 deg of attack, for all locations away from the nose, measurements were best matched with the aphysical supercatalytic boundary condition [10]. The authors commented that the uncertainty in the freestream (due to dissociation) was expected to explain some, but not all, of the discrepancies between heat transfer prediction and measurement. Laboratory experiments that investigated surface reactions involving dissociated $\mathrm{CO}_{2}$ found no evidence for the depletion of $\mathrm{CO}$ by surface reaction at either room temperature or at $250^{\circ} \mathrm{C}$ [11]. Such a result is inconsistent with the robust $\mathrm{CO}$ oxidation reactions required to enforce the supercatalytic boundary condition. This provides further motivation to collect additional data and compare heat transfer measurements with simulations incorporating catalytic boundary conditions.

At the cost of reduced test time and potential loss in core flow due to the development of the boundary layer in the acceleration section behind the transmitted shock [12-15], expansion tubes are capable of producing high-enthalpy conditions while the degree of freestream nonequilibrium effects is significantly reduced in comparison with reflected shock tunnels. In a reflected shock tunnel, chemical and vibrational freezing can occur downstream from the nozzle throat, which has been previously documented to alter the test conditions in a complex manner [16-18]. In the present work, the hypervelocity expansion tube (HET) is used to provide additional high-enthalpy $\mathrm{CO}_{2}$ data and comparison with the numerical result.
Several studies have examined the acceleration of $\mathrm{CO}_{2}$ to hypervelocity conditions in expansion tube facilities. Using the $\mathrm{X} 1$ facility [19] at the University of Queensland, Australia, to create flows with very high nominal enthalpies, Wegener et al. [20] investigated the effect of chemistry during the unsteady expansion process in the acceleration section and observed a trend toward equilibrium with higher enthalpies. Numerical simulations of a test condition in the JX-1 facility [21] at Tohoku University predicted only a very thin region of nonequilibrium directly behind the transmitted shock [22] at the moment when the transmitted shock wave arrives at the end of acceleration tube.

In this study, we first obtain a suitable test condition with firstorder matching of the high-enthalpy CUBRC test case. Next, spherical models of different diameters (7.9 to $63.5 \mathrm{~mm}$ ) are examined as a canonical flowfield for which shock standoff distance data are obtained for equilibrium, nonequilibrium, and frozen conditions, as predicted by theory. Sphere shock layer shapes are compared with axisymmetric simulations using the US3D code [23]. These comparisons are useful for additional verification of facility operation, as well as for validation of future computational simulations and thermochemical models. For the same test condition, shock shapes over a MSL model geometry at three flight angles of attack $(0,11$, and $16 \mathrm{deg})$ are obtained and also compared with simulations. At each angle of attack, surface heat flux measurements were made using coaxial thermocouples. The heat transfer distributions are compared with calculations assuming noncatalytic and supercatalytic boundary conditions.

\section{Experimental Setup}

The HET is a 9.14-m-long facility located at the University of Illinois and consists of three sections (driver, driven, and accelerator), all with a $150 \mathrm{~mm}$ inner bore diameter, initially separated by primary and secondary diaphragms (Fig. 1). The initial gas pressure and composition can be varied to achieve nominal Mach numbers of between 3.0 to 7.5 and stagnation enthalpies between 4.5 to $8.0 \mathrm{MJ} / \mathrm{kg}$. The facility is initially evacuated, and then each section is filled to the desired initial pressure. The primary diaphragm burst pressure (driver pressure) is measured using a Setra 206 pressure gauge. Driven and accelerator initial fill pressures are monitored

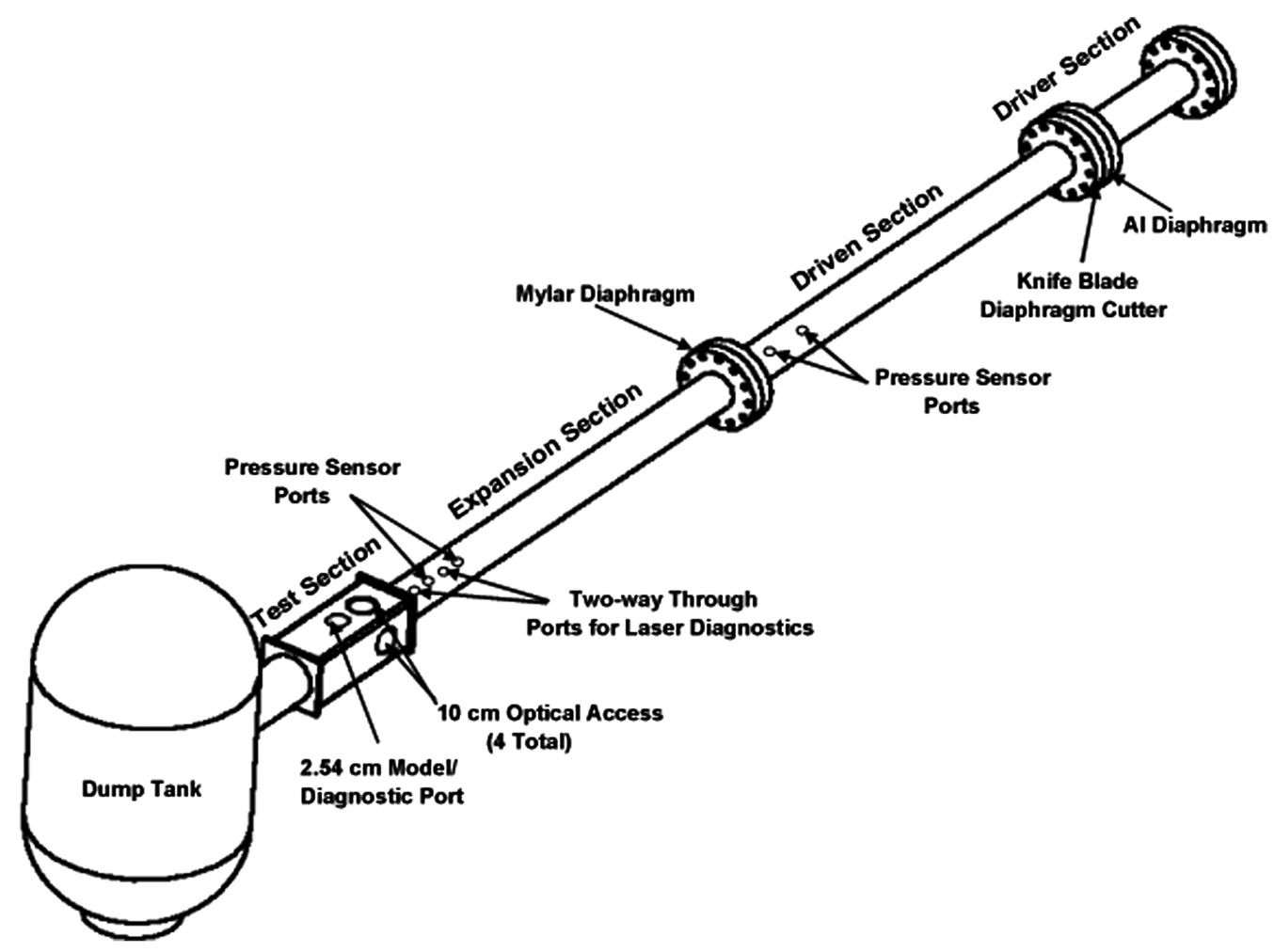

Fig. 1 Schematic of the HET facility, identifying its key features. 


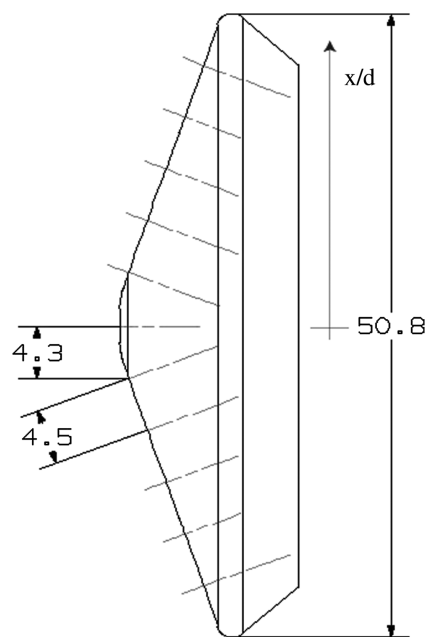

Fig. 2 MSL model used in the HET. Dimensions are in $\mathbf{m m}$. At the angle of attack, the windward and leeward sides will have negative and positive $x / d$ values, respectively.

using MKS Piezo+ A900-02 transducers. Vacuum pressures (below 2000 mtorr) in the accelerator section are measured using a MKS Baratron 626A transducer with a 2 torr full scale, rated to $0.25 \%$ of the reading. A full description of the facility, the measurement capabilities, and the facility operation can be found in Dufrene et al. [24]. Facility operation has been previously characterized experimentally and numerically $[24,25]$.

Shock shapes are visualized using a schlieren system consisting of a Xenon nanopulser (10 ns duration) white light source and a pco.1660 (Cooke Corporation) charge-coupled device camera with an exposure time of $5 \mu \mathrm{s}$. The system is triggered via the transmitted shock arrival at a $1 \mathrm{MHz}$ response pitot pressure transducer (PCB Piezotronics, Inc. 113A26) sting mounted in the test section $63.5 \mathrm{~mm}$ below the model centerline.

The spheres and the MSL are mounted within the test section, such that their axial centerlines approximately correspond with the tube centerline. The 11 and 16 deg angle-of-attack positions were achieved by mounting the MSL model on triangular spacer blocks, for which the hypotenuse was angled at the desired angle of attack from the vertical. The spheres and the MSL were made from Al 2024 and A2 tool steel, respectively. With a major diameter of $50.8 \mathrm{~mm}$, the MSL model used in this study is approximately $1 / 100$ th the size of the actual vehicle. The scaled-down dimensions of the MSL were designed according to those specified in Hollis et al. [26]. As with the actual vehicle, the model has a 70 deg sphere-cone forebody; however, the current model only has a single conic (40 deg) aftbody, while the actual vehicle is biconic. Figure 2 is a schematic of the MSL model used in the HET, with the thermocouple locations identified. Thermocouples located along the windward and leeward faces (all locations except for the stagnation point) are separated by $4.5 \mathrm{~mm}$.

The thermocouples used in these experiments are based on the design of Sanderson [27]. They are coaxial 2.4-mm-diam type E (Constantan-Chromel), and they mount flush with the surface of a model. The two coaxial elements are designed such that an extremely thin junction (on the order of $1 \mu \mathrm{m}$ ) is formed at the surface. This type of thermocouple gauge is used extensively in the T5 reflected shock tunnel [27-29], where the high-enthalpy test conditions result in adequate signal levels, and the robust design of the gauges make them highly resistant to damage caused by particulates in the test gas as well as the large heat fluxes [27]. The output signal is processed by a differential amplifier circuit mounted exterior to the test section. This also serves to eliminate the effects of any extraneous electromotive forces generated by the thermocouple. The circuit gain is 1000 to maximize signal amplitude. Individual calibration of thermocouples is not necessary, since the temperature response of all common thermocouple types is well known. The National Institute of Standards and Technology thermocouple reference tables were used to convert from voltage to temperature [30]. For more information regarding the development, testing, and performance verification of the thermocouples, see Flaherty and Austin [31].

\section{Numerical Modeling}

The simulations were conducted using code US3D developed at the University of Minnesota [23]. US3D is a hybrid, implicit unstructured finite-volume code that solves the compressible Navier-Stokes equations. The inviscid fluxes are calculated using a low-dissipation version of the Steger-Warming flux vector splitting. Second-order accuracy in space is achieved using an upwind-biased MUSCL approach. Implicit time integration is performed using a parallel-line relaxation procedure. The grid was adapted to align with the bow shock wave to improve the accuracy of the solutions.

The state-specific vibrational model of Doraiswamy et al. [32] for the $\mathrm{CO}_{2}-\mathrm{CO}-\mathrm{O}_{2}-\mathrm{O}$ system is employed for thermochemical modeling. In this model, the symmetric stretch and bending modes of $\mathrm{CO}_{2}$ are grouped together due to the Fermi resonance between the modes, and these modes are assumed to be in equilibrium with the translational modes. The antisymmetric mode is considered separately and relaxes toward equilibrium with finite-rate vibrationtranslation and vibration-vibration processes. The first few vibrational states are considered for each species up to a limit of $8000 \mathrm{~cm}^{-1}$ above the ground state. Each vibrational level is treated as a separate species, with a total of 15 state-specific levels considered (four levels for $\mathrm{CO}_{2}$, five levels for $\mathrm{CO}$, and six levels for $\mathrm{O}_{2}$ ). The vibrational relaxation model has been shown to reproduce experimentally observed relaxation times for each species pair, and a complete description is given in Doraiswamy et al [32].

The three chemical reactions that describe the $\mathrm{CO}_{2}-\mathrm{CO}-\mathrm{O}_{2}-\mathrm{O}$ system are taken to be

$$
\begin{gathered}
\mathrm{CO}_{2}+\mathrm{M} \leftrightharpoons \mathrm{CO}+\mathrm{O}+\mathrm{M} \\
\mathrm{O}_{2}+\mathrm{M} \leftrightharpoons \mathrm{O}+\mathrm{O}+\mathrm{M} \\
\mathrm{CO}_{2}+\mathrm{O} \leftrightharpoons \mathrm{CO}+\mathrm{O}_{2}
\end{gathered}
$$

Standard rate constants for these reactions are used [32].

\section{Results and Discussion}

\section{A. Criteria for Selection of Experimental Test Conditions}

Carbon dioxide test gas conditions are selected to match the relevant experimental parameters in the CUBRC facilities as closely as possible. Since, in general, all test parameters cannot be matched from facility to facility, identification of the dominant flow properties for a particular measurement is important in comparative ground testing as well as in flight simulation. One aspect of the present study is to evaluate what parameters should be matched for adequate comparative measurements of shock shape and heat transfer in different expansion tube facilities. Simulations of blunt bodies in nitrogen flows by Macrossan showed that freestream dissociation had little effect on the bow shock at different angles of attack [33], indicating that, in nitrogen, the degree of dissociation in shock tunnel versus flight tests was less important to match than the Mach number.

The discrepancy between the CUBRC LENS X and LENS I results was observed for test conditions with $5.63 \mathrm{MJ} / \mathrm{kg}$ stagnation enthalpy in $\mathrm{CO}_{2}$ [2]. For the same stagnation enthalpy, we select the test gas velocity as the first-order matching parameter due to the large kinetic energy contribution to the total enthalpy. Matching the CUBRC condition in the HET requires a test gas velocity of $3036 \mathrm{~m} / \mathrm{s}$. Higher-order matching could be achieved by using the frozen Mach number as a selection parameter; however, the LENS X run condition frozen Mach number is 11.81 , which is outside the operating regime of the HET.

In an expansion tube, for a fixed test gas composition and driver pressure, test gas properties can be changed by either altering the initial driven pressure $p_{1}$ or the initial acceleration section conditions $\left(\gamma_{5}, p_{5}\right)$. Table 1 presents properties for four different run conditions. 
Table 1 Properties for candidate HET test conditions - $^{\mathrm{a}}$

\begin{tabular}{|c|c|c|c|c|c|c|c|c|c|}
\hline Interface & $p_{1}, \mathrm{kPa}$ & $p_{5}$, mtorr & $u_{7}, \mathrm{~m} / \mathrm{s}$ & $h_{\text {stag }, 7}, \mathrm{MJ} / \mathrm{kg}$ & $M_{7}$ & $T_{7}, \mathrm{~K}$ & $\rho_{7}, \mathrm{~kg} / \mathrm{m}^{3}$ & $u_{t}, \mathrm{~m} / \mathrm{s}$ & Test time, $\mu \mathrm{s}$ \\
\hline $\mathrm{CO}_{2}-\mathrm{CO}_{2}(\mathrm{RC} 2)$ & 1.2 & 150 & 2998 & 5.51 & 5.52 & 1212 & 0.016 & 3454 & 293 \\
\hline $\mathrm{CO}_{2}$-Air (RC5) & 1.2 & 180 & 3059 & 5.66 & 5.72 & 1172 & 0.014 & 3698 & 274 \\
\hline $\mathrm{CO}_{2}$ - $\mathrm{Hel}(\mathrm{RC} 8)$ & 1.2 & 1050 & 3066 & 5.68 & 5.75 & 1168 & 0.014 & 4328 & 272 \\
\hline $\mathrm{CO}_{2}-\mathrm{Arg}(\mathrm{RC} 11)$ & 1.2 & 135 & 3014 & 5.55 & 5.57 & 1201 & 0.016 & 4045 & 288 \\
\hline
\end{tabular}

${ }^{a}$ Initial fill conditions differ by the choice of acceleration gas.

In each case, the test gas velocity is within $1.3 \%$ of the CUBRC test gas velocity. Transmitted shock velocity is typically accurate to within $\pm 43 \mathrm{~m} / \mathrm{s}$ in the HET, and it is expected that similar error bars will exist for test gas velocity measurements [34]. In the first column, the test conditions were generated by varying the acceleration section gas; here, argon, helium, air, and carbon dioxide are used. The test conditions are described in terms of the driven-accelerator gas combination. The driven section pressure $p_{1}$ is kept constant in each case, and $p_{5}$ is chosen to match the test gas velocity requirement. In each case, the driver gas is helium, and the driver pressure is kept constant at roughly $2.5 \mathrm{MPa}$.

Additional criteria are then considered to achieve a wellcharacterized and uniform freestream. The expanded driver to driven gas sound speed ratio should be maintained below certain threshold values to reduce freestream disturbances $[24,35]$. The test time begins with the arrival of the driven to accelerator (secondary) gas interface, and the broadening of this interface should be minimized. Significant distortion of the contact surface and test time reduction was reported when carbon dioxide was used in both driven and accelerator sections in the JX-1 facilty [22]. To minimize broadening, air is selected as the accelerator gas.

Estimates of the shock standoff distance were made for candidate test conditions using the theory of Wen and Hornung [4]. For nonequilibrium flows, Lick applied inverse methods to calculate shock shape in front of a sphere [36], and his work was extended by Hall et al. [37]. Using the ideal dissociating gas model (diatomic gas), Hornung investigated nonequilibrium flow over spheres and cylinders [38]. Extending Hornung's original work to more complex gases, Wen and Hornung carried out a joint theoretical and experimental study of nonequilibrium dissociating flow over spheres and developed a model for the standoff distance in terms of a modified dimensionless reaction rate parameter [4]. Inger et al. presented a hypersonic shock standoff theory, incorporating nonequilibrium gas mixtures with freestream dissociation, based upon a compressibility coordinate transformation [39]. A theoretical model for the nonequilibrium shock standoff distance was also introduced by Belouaggadia et al [40], following an analytical solution proposed by Olivier [41]. The Olivier solution was confined to frozen and equilibrium flows, while the numerical model of Belouaggadia et al. [40] implemented calculated density profiles. At the postshock-toequilibrium density ratios in the present experiments, we find there is very little difference between density profiles calculated by the Wen and Hornung [4] and Belouaggadia et al. [40] methods. As a result, the theory of Wen and Hornung [4] is used in this study.

The shock standoff distance is known to be inversely proportional to the average density on the stagnation streamline $[4,38]$. In their inviscid analysis, Wen and Hornung [4] assumed a simplified density profile along the shock stagnation line. They defined a nondimensional shock standoff distance $\tilde{\Delta}$ as

$$
\tilde{\Delta}=\frac{\rho_{s}}{\rho_{\infty}} \frac{\Delta}{d}
$$

where $\rho_{\infty}$ is the freestream density, $\Delta$ is the shock standoff distance, and $d$ is the sphere diameter. The theory admits the calculation of $\tilde{\Delta}$ in terms of a dimensionless reaction rate parameter $\tilde{\Omega}$. $\tilde{\Omega}$ has the physical significance of being the ratio of the energy absorption rate by chemistry to the freestream kinetic energy input rate. Physically, a zero $\tilde{\Omega}$ corresponds to frozen conditions (no dissociation), and an infinite value corresponds to very fast reactions and equilibrium. In between these two limits, two conditions exist: a fully nonequilibrium shock layer and a shock layer with both nonequilibrium and equilibrium portions. Wen and Hornung [4] derived the following relationships for a fully nonequilibrium shock layer and a partial nonequilibrium, partial equilibrium shock layer, respectively,

$$
\begin{gathered}
\tilde{\Delta}=\frac{1}{\tilde{\Omega}}[-1+\sqrt{1+2 L \tilde{\Omega}}] \\
\tilde{\Delta}=\frac{\rho_{s}}{\rho_{e}}\left[L+\frac{1}{2 \tilde{\Omega}}\left(\frac{\rho_{e}}{\rho_{s}}-1\right)^{2}\right]
\end{gathered}
$$

where $\rho_{e}$ and $\rho_{s}$ are the equilibrium and postshock density, respectively, and $L$ is taken to be equal to 0.41 for spheres [4]. The Mach numbers for the four test conditions are very similar; hence, the variation in shock standoff distance will be very small. Therefore, no effective experimental benefit in terms of the shock standoff distance is achieved by selecting one condition over another. For a $50.8 \mathrm{~mm}$ sphere with a frozen shock layer $(\tilde{\Omega}=0)$, the shock standoff distance across the four candidate run conditions varies by only $0.3 \mathrm{~mm}$, which offers no experimental advantage.

Based on the previous considerations, a helium driver and air accelerator section test condition was selected and denoted as RC5. The test gas properties are computed with inviscid, unsteady onedimensional gas dynamic calculations and are presented in Table 2, together with corresponding experimental measurements. The shock speed in the driven section is $u_{s}$, and $u_{t}$ is the transmitted shock velocity in the accelerator gas. All the experimental values are averaged values across a number of realizations for repeatability. The pitot pressure measurements were obtained $6.35 \mathrm{~mm}$ below the tube centerline. Static pressure values were obtained at two stations, 30.48 and $55.88 \mathrm{~cm}$, upstream from the tube exit.

There is a discrepancy between the experimental and theoretical pitot pressure values. The theoretical test gas pitot pressure is calculated assuming an inviscid, perfect gas. The equilibrium pitot pressure is calculated to be $119 \mathrm{kPa}$, clearly not a sufficient reduction to match the experimental value. The discrepancy in pitot pressure is currently under investigation. The transmitted shock speed was also measured in the test section using the shock time of arrival at staggered pitot probes. This approach has been used in the past to characterize a test condition and, in that instance, it was found that the measurement agreed with the computational results [42]. Experimental pitot surveys of the core flow at this test condition were carried out to determine that the maximum model diameter that can

\begin{tabular}{|c|c|c|c|c|c|c|c|c|}
\hline & $M_{7}$ & $h_{\text {stag }, 7}, \mathrm{MJ} / \mathrm{kg}$ & Test time, $\mu \mathrm{s}$ & $p_{7, \text { pitot }}, \mathrm{kPa}$ & $p_{7}, \mathrm{kPa}$ & $u_{t}, \mathrm{~m} / \mathrm{s}$ & $u_{7}, \mathrm{~m} / \mathrm{s}$ & $\overline{u_{s}, \mathrm{~m} / \mathrm{s}}$ \\
\hline Experiment & $\overline{ }$ & $\bar{n}$ & 150 & $82.0 \pm 4.0$ & $2.7 \pm 0.3$ & $3644 \pm 41$ & $\overline{-}$ & $1832 \pm 38$ \\
\hline Theoretical & 5.7 & 5.67 & 274 & 128.3 & 3.2 & 3710 & 3059 & 1853 \\
\hline
\end{tabular}
be chosen is about $65 \mathrm{~mm}$.

Table 2 Selected test condition parameters ${ }^{\mathrm{a}}$

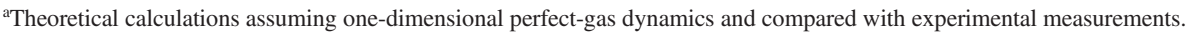




\section{B. Sphere Shock Shapes}

We initially examined spherical models in benchmark tests for which the results could be compared with existing experimental data and theoretical predictions. This flowfield provides additional verification of facility operation via numerical simulations and thermochemical calculations with a relatively simple geometry. Shock standoff distances over a sphere have been previously investigated in nonequilibrium air and nitrogen flows $[38,43]$. As discussed in Sec. I, Wen and Hornung measured shock standoff distances over spheres in a high-enthalpy carbon dioxide flowfield [4]. Outstanding issues in a carbon dioxide flowfield still remain, including the role of thermochemical energy storage and transfer and the possibility of facility-specific data. Therefore, the measurement of the shock standoff distance for similar enthalpy conditions in another hypervelocity facility provide data to complement existing results.

Selected schlieren images for spheres of diameters from 25.4 to $63.5 \mathrm{~mm}$ are shown in Figs. $3 \mathrm{a}-3 \mathrm{~d}$ and compared with numerical simulations. Experimental images have been rescaled to the same sphere size in postprocessing. Numerical simulations were carried out at the freestream conditions predicted by the ideal gas theory (Table 2).

Normalized vibrational temperatures are shown in Figs. 4a-4d. For all the spherical geometries, the simulated temperature contours predict that the majority of the stagnation line shock layer is in equilibrium, and only a small nonequilibrium region exists near the bow shock.

The $\tilde{\Delta}-\tilde{\Omega}$ curve of Wen and Hornung [4] for RC5 is compared against the experimental results (Fig. 5). Here, the $y$ axis is slightly recast as another nondimensional shock standoff distance $\frac{\Delta}{d}$. For each sphere, the reaction rate parameter is calculated according to

$$
\tilde{\Omega}=\frac{d}{\rho_{s} u_{\infty}}\left(\frac{1}{h_{\rho}} \sum_{i=2}^{n} h_{c_{i}} \frac{\mathrm{d} c_{i}}{\mathrm{~d} t}\right)_{s}
$$

where $d$ is the sphere diameter, $u_{\infty}$ is the freestream velocity, and $c$ is the mass fraction. Subscripts $i$ and $s$ refer to individual species and postshock values, respectively. The partial derivatives of the static enthalpy with respect to the density and species mass fractions are $h_{\rho}$ and $h_{c}$, respectively. The postshock mass fraction rates are supplied from the numerical calculations. The postshock conditions directly behind the shock are taken to be the values at which the translational temperature is a maximum.

The predicted values of $\Delta$ for the four spheres from the theory of Wen and Hornung [4], based upon the calculated $\tilde{\Omega}$ values, are presented in Table 3. It is clear from both the table and Fig. 5 that the theoretical prediction does not represent the experimental result. In the table, the percentage difference between theory and experiment is included in parentheses. The differences are quite large, but more concerning is that the values do not even match the characteristic shape of the $\tilde{\Delta}-\tilde{\Omega}$ curve. For their theory to be applicable, Wen and Hornung require that the binary scaling $\rho d$ be sufficiently large. Wen establishes a rule of thumb for binary scaling; however, this is valid only for a diatomic gas [44]. In the work of Wen and Hornung [4], the sphere diameters ranged from 2 to 6 in., and the freestream densities were considerably higher, resulting in $\rho d$ values that were an order of magnitude larger than the RC5 value. For example, for a comparable stagnation enthalpy and Mach number run condition, the maximum T5 $\rho d$ value is $6.87 \times 10^{-3}$, while the maximum HET value is $9.14 \times 10^{-4}$. The results from the T5 facility saw good to very good agreement between the binary-scaling-based theory and the experimental measurement for stagnation enthalpies ranging from 4.11 to $10.76 \mathrm{MJ} / \mathrm{Kg}$ in nitrogen and $\mathrm{CO}_{2}[4,44]$. It therefore appears that the binary scaling values of this study are too small for the experimental conditions to be applicable to Wen and Hornung's theory [4].

Shock standoff distances based upon the theory of Inger et al. [39] were also calculated. The theory implements a compressibility coordinate transformation. It is an inviscid approximation. In their paper, Inger et al. obtained good agreement with the experimental data of Wen and Hornung [4]. The calculated results are also shown in Table 3 . The percentage difference between experiment and theory are shown in parentheses. The coordinate transformation approach has captured the trend observed in the experimental data of an increasing shock standoff distance with an increasing sphere diameter. The theory overpredicts both the experimental measurement and the numerical result, with an experimental overprediction of up to $29 \%$. Based upon these results, it appears that the compressibility coordinate transformation approach is capable of providing a reasonable approximation of shock standoff distances in nonequilibrium gas flows for low-density small-scale conditions that otherwise appear not to be applicable for the theory of Wen and Hornung.

\section{Mars Science Laboratory Shock Shapes at Angle of Attack}

Experimental images and numerical simulations of the bow shock shape over the MSL geometry at three angles of attack are shown in Fig. 6. Images show increasing shock standoff distance with increasing angle of attack. In the nonzero angle-of-attack images (in particular, for the $16 \mathrm{deg}$ case), the shock appears to be spherically shaped on the windward side and more conically shaped over the leeward side. Similar results were also observed by Stewart and Chen [3]. For the 16 deg case (Fig. 6c), the maximum bow shock gradient with respect to the horizontal (freestream) has shifted toward the windward side. As measured from the experiment, the vertical shift of this location is $8.5 \mathrm{~mm}$. To quantify the comparison between the predictions and experiments, an edge detection algorithm was used to extract the shock shape. For the $11 \mathrm{deg}$ case, the average horizontal displacement at each given vertical location between numerical and experimental results is 1.64 pixels. With a minimum resolution of 1 pixel, restricting the accuracy to approximately $0.06 \mathrm{~mm}$, this agreement is excellent, as seen in Fig. 7, which shows the comparison between simulation and experiment. The $16 \mathrm{deg}$ case is also shown

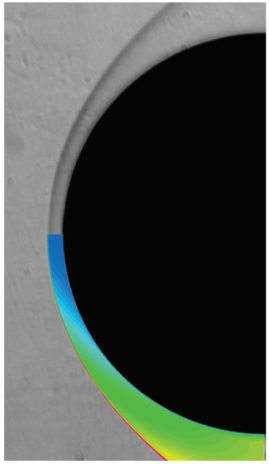

a)

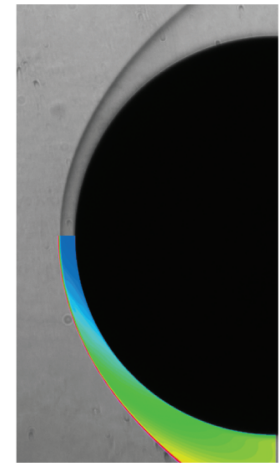

b)

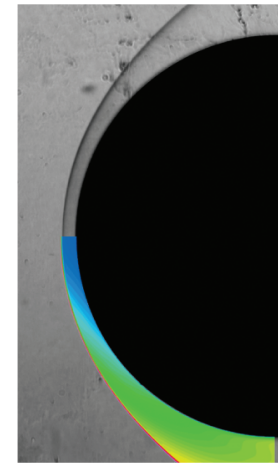

c)

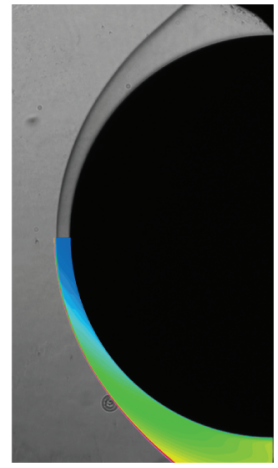

d)

Fig. 3 Comparisons of experimental schlieren images and simulations of bow shock shapes over spheres of diameter a) 25.4, b) 37.5 , c) 50.8 , and d) $63.5 \mathrm{~mm}$. 


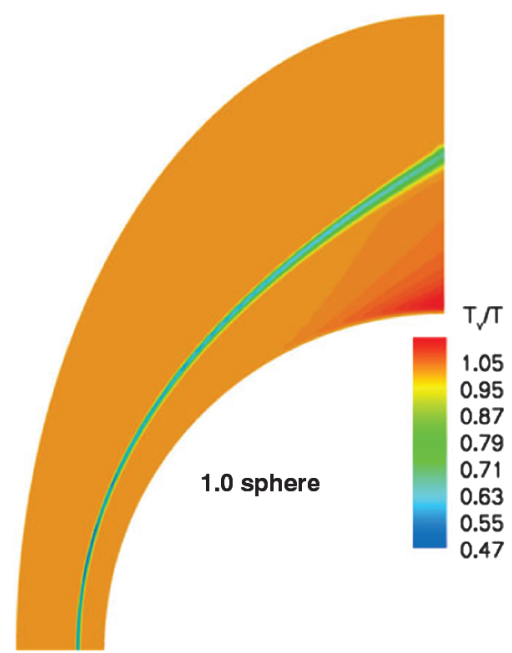

a)

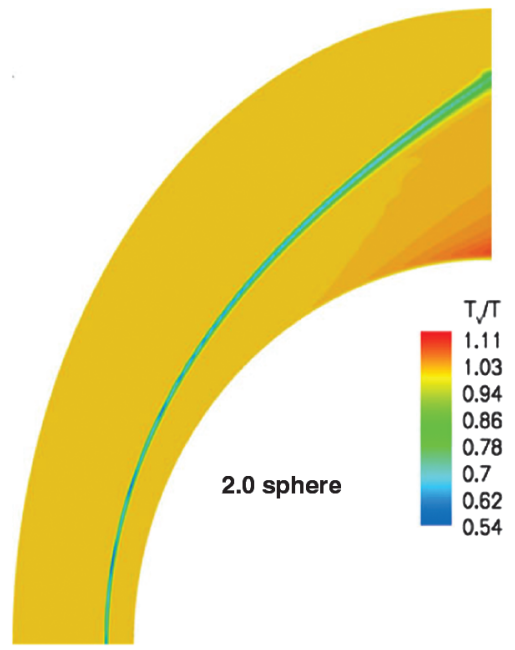

c)

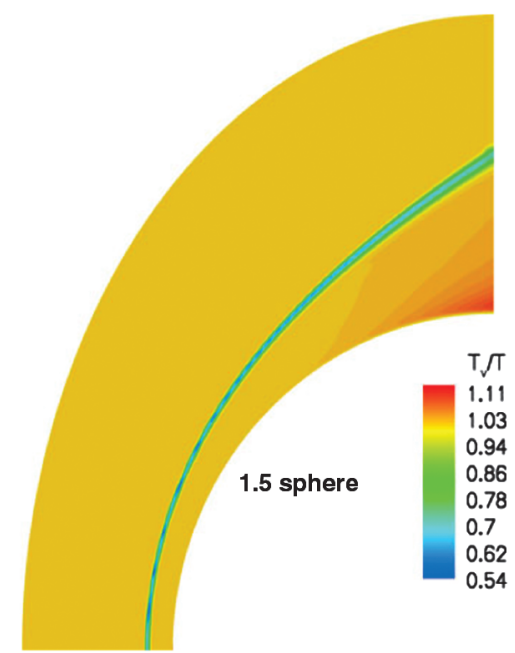

b)

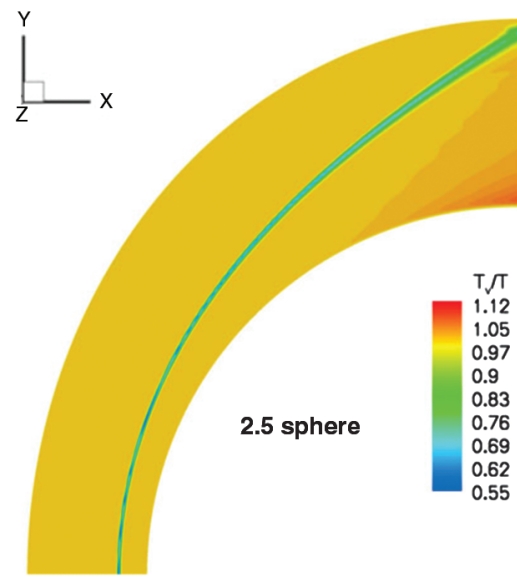

d)

Fig. 4 Vibrational temperature contours from US3D simulations for sphere diameters of a) 25.4, b) 37.5 , c) 50.8 , and d) $63.5 \mathrm{~mm}$.

(Fig. 8), for which the average horizontal displacement was calculated to be 2.49 pixels.

We compare the measured shock shape at a 0 deg of attack with the experimental and computational results from previous studies (Fig. 9). The standoff distance is a strong function of the density ratio across the shock. Despite the difference between the LENS X and the HET frozen Mach numbers, the density ratios differ by about $15 \%$ and, as such, to the first order, it is appropriate to scale the images by the model diameter. Therefore, to the first order, we see very good agreement between our result and that observed in the LENS $\mathrm{X}$ expansion tunnel [1]. Calculated shapes at the conditions of the LENS X experiments are also in good agreement with the present measurements.

\section{Laminar Heat Flux and Catalytic Heating}

Extensive work has been completed using heat transfer measurements for $\mathrm{CO}_{2}$ aerothermodynamic studies. For a configuration with a similar corner-nose radius ratio as the MSL, Stewart and Chen reported a $13.76 \%$ difference between the experiment and the simulation [3]. For the Pathfinder geometry (70 deg sphere cone), Hollis and Perkins measured heat transfer on Macor models using palladium thin-film gauges [7]. Computed forebody heating rates agreed well with measurements, except those readings near the stagnation point [45]. They attributed this difference to the computational grid and uncertainties in the physical models. For a variety of run conditions, Hollis et al. [45] found that windside heating augmentation was not correlated with Reynolds numbers despite such a correlation being identified in perfect-gas air flows for the same configurations [26]. Thermocouple data were obtained for a variety of run conditions in the T5 facility [8]. In a LENS I study, thermocouple data were collected on a MSL model at an $11 \mathrm{deg}$ angle of attack [46]. Based upon these results, and at the same conditions, further studies were commissioned and heat transfer data were collected using thermocouples, thin-film gauges, and calorimeters [10].

Table 3 Comparison between the experimental shock standoff distance, the numerical result from US3D, and the two theoretical solutions

\begin{tabular}{ccccc}
\hline \hline Sphere diameter, $\mathrm{mm}$ & $\Delta_{\text {exp }}, \mathrm{mm}$ & $\Delta_{\text {num }}, \mathrm{mm}(\mathrm{US3D})$ & $\Delta_{\text {theory }}, \mathrm{mm}$ (Wen and Hornung [4]) & $\Delta_{\text {theory }}, \mathrm{mm}$ (Inger et al. [39]) \\
\hline 63.5 & 2.29 & $2.45(7.0)$ & $2.76(20.5)$ & $2.77(21.0)$ \\
50.8 & 1.89 & $1.98(4.8)$ & $2.97(57.1)$ & $2.43(28.6)$ \\
38.1 & 1.44 & $1.53(6.3)$ & $2.28(58.3)$ & $1.65(14.6)$ \\
25.4 & 1.13 & $1.06(-6.2)$ & $1.49(31.9)$ & $1.16(2.7)$ \\
\hline \hline
\end{tabular}




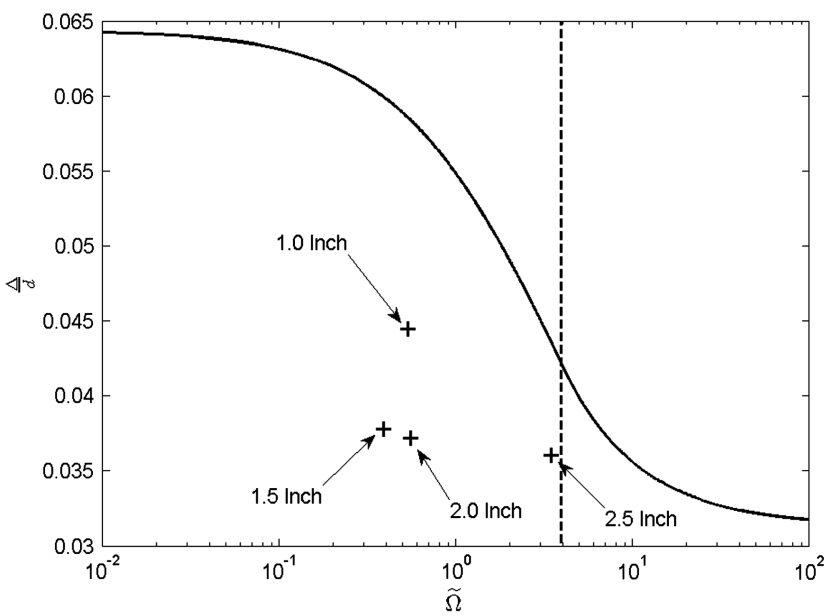

Fig. 5 Comparison of normalized experimental standoff distance (crosses) with theoretical prediction (solid line). The point where $\rho_{b}=\rho_{e}$, separating a fully nonequilibrium shock layer from a partial equilibrium/partial nonequilibrium region, is indicated by the dashed vertical line.

Extensive investigations into the influence of wall catalysis boundary conditions, such as noncatalytic and supercatalytic, upon surface heating in high-enthalpy carbon dioxide flowfields, have been completed in the LENS facilities $[10,26]$. A noncatalytic boundary condition results in the lowest heating rates, as no recombination occurs, while the supercatalytic case assumes full recombination at the surface regardless of the local equilibrium conditions. It represents the upper bound on the heat transfer prediction as the gas is returned to its lowest chemical state; hence, the maximum amount of heat is released. MacLean and Holden [2] compared heat transfer results with different catalytic boundary conditions. Discrepancies between the experimental surface heat transfer results and computation in the reflected shock-tunnel facilities for three different high-enthalpy $\mathrm{CO}_{2}$ run conditions $\left(h_{0}=5.63,5.99\right.$, and $\left.8.65 \mathrm{MJ} / \mathrm{kg}\right)[10]$ were observed. At the lowenthalpy condition $\left(h_{0}=1.89 \mathrm{MJ} / \overline{\mathrm{kg}}\right)$, the overall agreement was very good. MacLean and Holden [2] concluded that freestream uncertainty, hence vibrational relaxation processes within the nozzle, is a contributing factor to, although not a full explanation of, these differences. Results from the CUBRC studies found that the experimental heating rates fell between noncatalytic and supercatalytic boundary conditions, which suggested that finite-rate catalysis existed at all points on the surface [10].

As previously discussed in Sec. II, heat flux in this study is measured using in-house-constructed type E thermocouples based

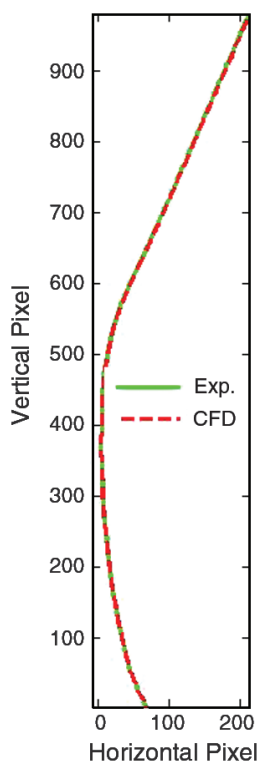

Fig. 7 Comparison between experimental (solid line) and numerical (dashed line) bow shock front shapes over the MSL at an angle of attack of $11 \mathrm{deg}$. One pixel is approximately equal to $0.06 \mathrm{~mm}$. CFD denotes computational fluid dynamics.

upon designs used at the California Institute of Technology. The gauge uncertainty is $\pm 8 \%$, based upon the calculations of Davis [28]. We first measure the stagnation point heat flux measurements on a 25.4-mm-diam stainless steel sphere. From three repeat experiments, the average heat flux across the test time is found to be $6.73 \pm 0.55 \mathrm{MW} / \mathrm{m}^{2}$. The semiempirical prediction of Sutton and Graves [47], which is an extension of the theory of Fay and Riddell [48], and the US3D numerical results were used for comparison. The theory of Fay and Riddell assumes an equilibrium boundary layer (as does the work of Sutton and Graves [47]), which is reasonable given the extent of the equilibrium region in the shock layer predicted in Fig. 4a. The prediction of Sutton and Graves is $6.85 \mathrm{MW} / \mathrm{m}^{2}$, which agrees well within the experimental uncertainty of the gauges. The upper and lower bounds of the US3D prediction, corresponding to supercatalytic and noncatalytic simulations, respectively, were 7.34 and $6.93 \mathrm{MW} / \mathrm{m}^{2}$, placing the experimental result closer to a noncatalytic wall.

Since the MSL model was constructed of tool steel, two cylindrical models, one of 316 stainless steel and one of A2 tool steel, were next tested. Both cylinders were instrumented with a gauge mounted on the vertical axis of symmetry at a $45 \mathrm{deg}$ angle. Figure 10 shows the

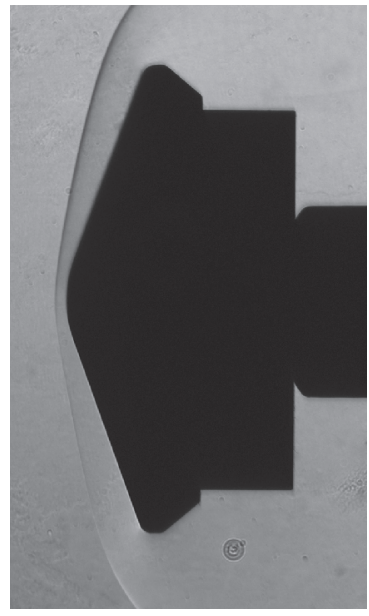

a)

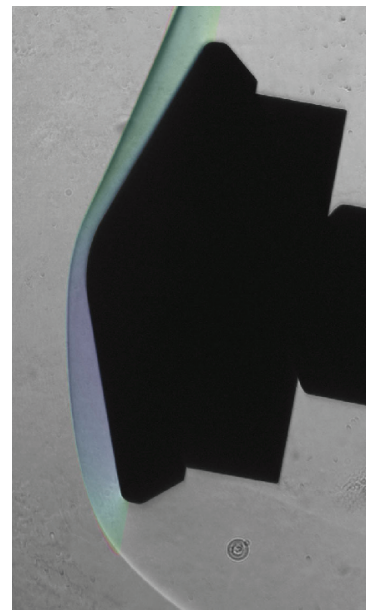

b)

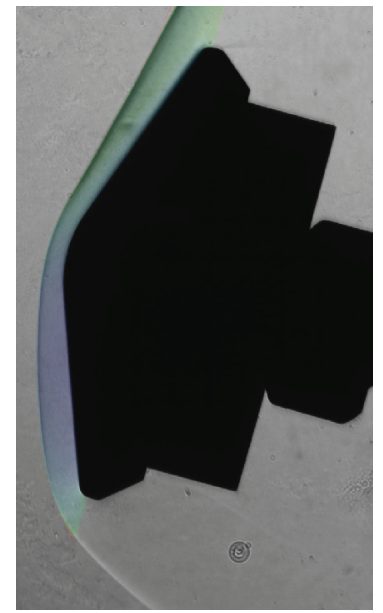

c)

Fig. 6 Schlieren images of bow shock shapes over the MSL geometry at angles of attack of a) 0 , b) 11, and c) 16 deg. For the 11 and 16 deg cases, the simulation results have been overlaid onto the experimental image. 


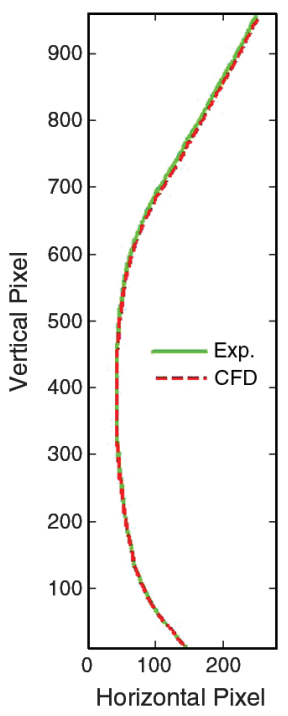

Fig. 8 Comparison between experimental (solid line) and numerical (dashed line) bow shock front shapes over the MSL at an angle of attack of $16 \mathrm{deg}$. One pixel is approximately equal to $0.06 \mathrm{~mm}$.

comparison between two gauges in terms of the detected temperature rise. The temporal offset occurs only due to shot-to-shot variation in triggering. For heat transfer calculation, it is the gradient of the temperature history that is important and, as shown in Fig. 10, the gradients appear to be very similar. At the 45 deg location, the average heat flux measured in repeat experiments was 2.55 and $2.53 \mathrm{MW} / \mathrm{m}^{2}$ on the tool and stainless steel models, respectively. It is concluded that the heat flux measurements are not influenced by the model material for these two steels.

A sample heat flux measurement obtained at the MSL nose for a 0 deg angle of attack is shown in Fig. 11. The test time as measured from the pitot trace begins at $12.9 \mathrm{~ms}$. However, at the beginning of the test time, it was observed that the instantaneous heat flux exhibited transient behavior, displaying primary and secondary peaks, as seen in Fig. 11. The primary large peak is always observed, while the secondary smaller peak is not always present. It is
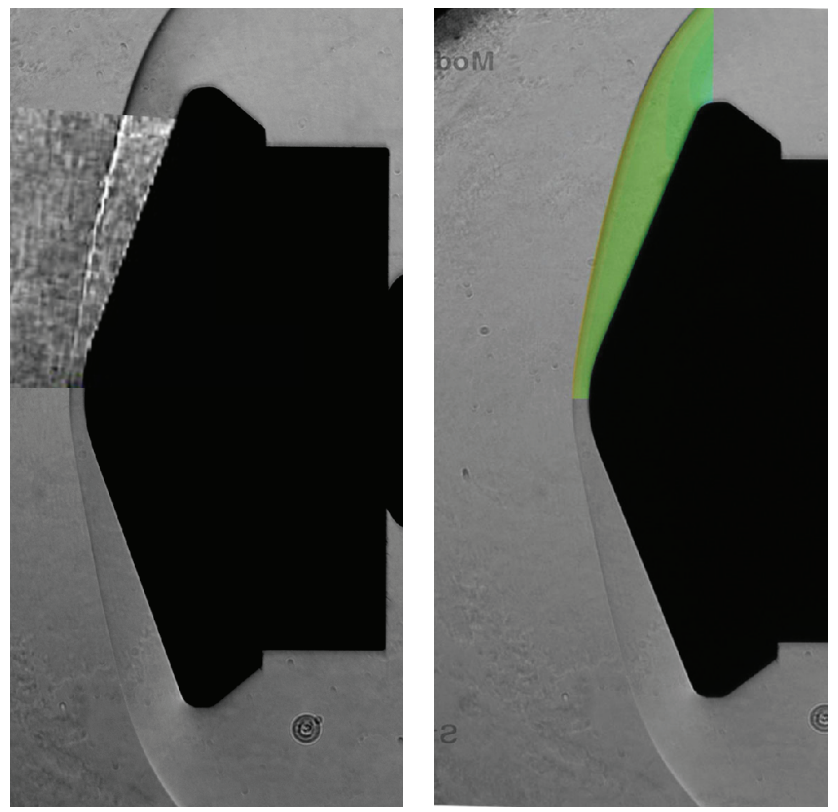

a)

b)

Fig. 9 Comparison of the present data with a) CUBRC LENS X data [1] and b) data parallel line relaxation simulations for the MSL model at a 0 deg of attack [1]. Good agreement is observed with the simulations and for both expansion tunnel experiments.

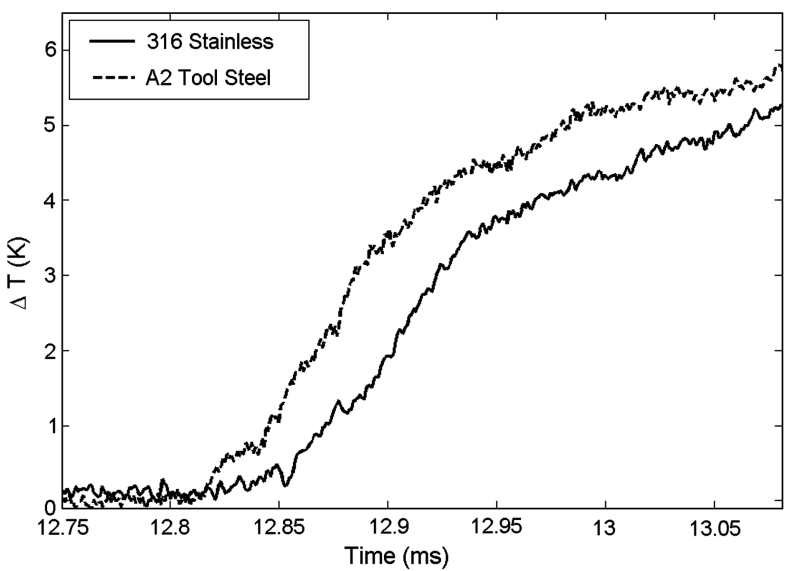

Fig. 10 Change in temperature time history traces detected by two different thermocouples on $\mathrm{A} 2$ and 316 stainless steel cylinder models.

postulated that the steep increase in heat flux is a perturbed response of the gauges arising from the sharp temperature difference across the secondary interface, separating the relatively hot accelerator gas from the relatively cold test gas. From perfect-gas predictions, this temperature difference is estimated to be approximately $5700 \mathrm{~K}$. Pitot pressure traces indicate that the width of the secondary interface is approximately $5 \mu \mathrm{s}$, which is on the same order as the width of the primary peak in Fig. 11. To examine the effect of the transient behavior, the average heat flux is calculated for different sampling windows (Fig. 11). In each calculation, the end of the test time is fixed (in this case, at $13.06 \mathrm{~ms}$ ), and the sampling window is changed by changing the start of the test time $t_{\text {start }}$. For example, in the figure, as $t_{\text {start }}$ increases along the abscissa, the sampling window decreases. As the sampling window includes less and less of the peaks, the instantaneous and average traces converge. Furthermore, as expected based upon the large magnitude of the primary peak, the gradient of the average heat flux is much more pronounced when the primary peak is included in the calculation. Therefore, the incipient heat flux behavior is attributed to gauge acclimatization to the large temperature difference across the secondary interface and, as such, is not included in the average heat flux calculation. The heat flux measurement is taken as the average value once the instantaneous heat flux falls within $15 \%$ of the average value. For example, in this case, the start of the heat flux data acquisition is taken to be $12.97 \mathrm{~ms}$, and the average is over a $90 \mu$ s window.

The MSL model was instrumented with 11 thermocouples along the line of symmetry, with five on each side of the nose location. Repeat experiments were conducted for each of the three angle-ofattack conditions. The heat transfer distributions at the three angles of

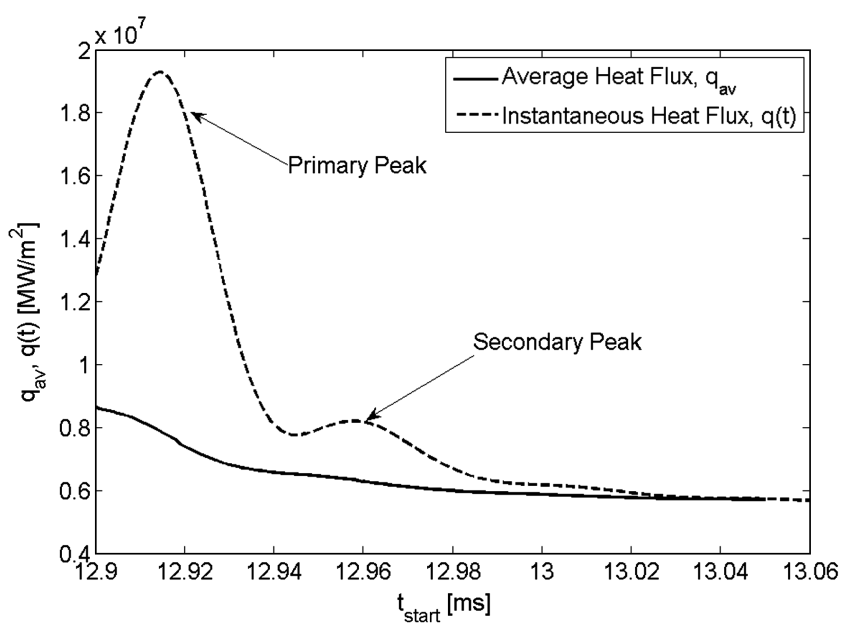

Fig. 11 Comparison of instantaneous heat flux and the calculated heat flux during the test time. The start of the heat flux data acquisition is taken to be $12.97 \mathrm{~ms}$, and the average is over a $90 \mu$ s window. 


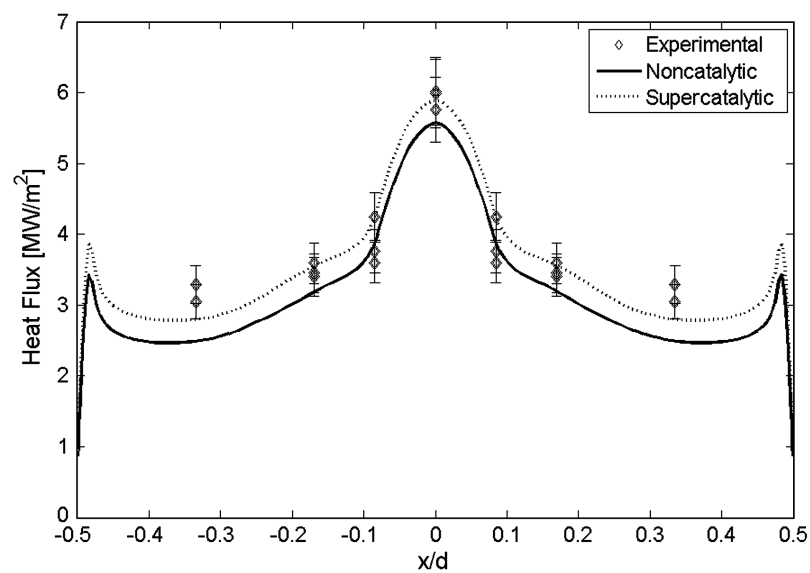

Fig. 12 Heat flux measurements at selected locations along the centerline of the MSL geometry for a 0 deg angle of attack. Numerical simulations for both noncatalytic and supercatalytic conditions are shown.

attack are shown in Figs. 12-14. Measurements were taken at selected locations, corresponding to the nose tip and $\pm 4.3,8.6$, and $17 \mathrm{~mm}$ offset from the nose tip. The windward side corresponds to negative $x / d$. The results from these distributions capture the general trends observed in previous blunted cone studies $[3,8,10,26]$. The nose heat transfer decreases with increasing angle of attack, which is

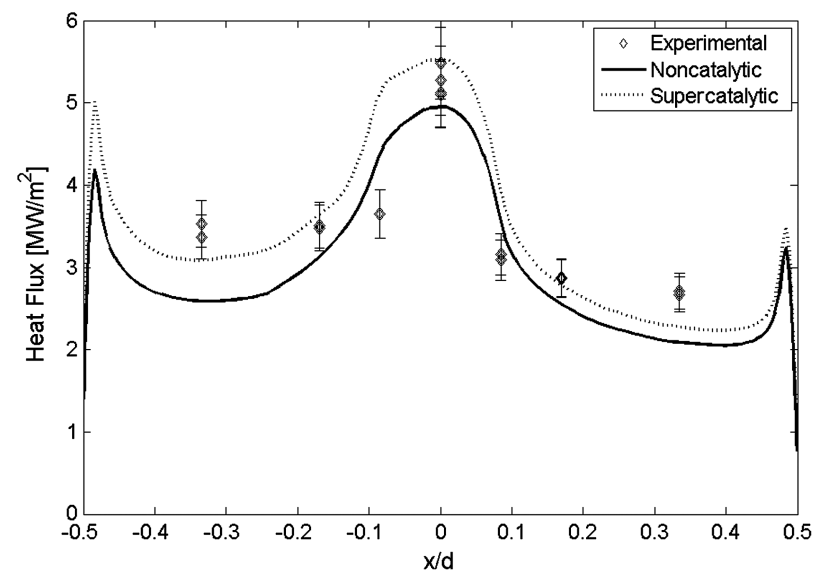

Fig. 13 Heat flux measurements at selected locations along the centerline of the MSL geometry for an 11 deg angle of attack. Numerical simulations for both noncatalytic and supercatalytic conditions are shown.

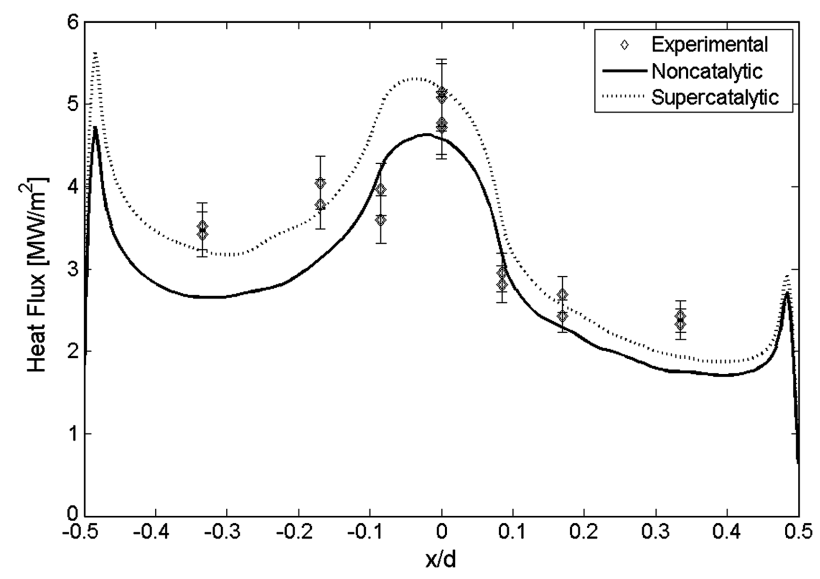

Fig. 14 Heat flux measurements at selected locations along the centerline of the MSL geometry for a 16 deg angle of attack. Numerical simulations for both noncatalytic and supercatalytic conditions are shown. indicative of the stagnation point shifting to the windward side. At $16 \mathrm{deg}$, the average measured heat flux is $5.11 \mathrm{MW} / \mathrm{m}^{2}$, which is approximately a $14 \%$ reduction when compared with the $0 \mathrm{deg}$ configuration. The windside movement of the peak heating location with an increasing angle of attack is captured in the simulations, as seen in Figs. 12-14; however, due to limited experimental spatial resolution, this peak heating value cannot be measured. Consistent with other studies, the windside heat fluxes are less sensitive to angleof-attack changes than those on the leeside. At a nonzero angle of attack, and for a given $x / d$ magnitude, the leeside values are lower than the windside values, as the shock angle (with respect to the freestream) is lower. The leeside heat fluxes decrease with an increasing angle of attack as the leeside conical shock angle also decreases with the angle of attack. Additionally, the asymmetric nature of the curve has been captured at the 11 and 16 deg cases, whereby the leeward-side measurements (at the same radial location magnitude) are lower than those on the windward side. For the current experiments, no transition is expected or observed given the Reynolds number and the scale of the model.

In each case, for Figs. 12-14, the experimental measurement is compared with noncatalytic and supercatalytic surface boundary condition simulations. In general, accounting for the experimental uncertainty, the data fall within the bounds of the two solutions. The relative difference between the noncatalytic and supercatalytic solutions is not as large in the HET data when compared with LENS I data for the same stagnation enthalpy and, unfortunately, this smaller difference and the experimental uncertainty of the gauges means that it is not possible to conclude which boundary condition provides the best agreement in the present data.

At all three angles of attack, experimentally measured heat fluxes at the outermost extent of the model are above the supercatalytic solution. Such a result appears to be anomalous as the supercatalytic solution enforces full surface recombination, regardless of the local species mole fractions and, therefore, represents an aphysical upper bound on the heat flux. Hollis et al. [45] observed windside heating augmentation, which was not found to correlate with the Reynolds number, in the LENS I facility [26]. In this study, however, both windside and leeside elevated heating levels are observed. At this stage, the reason for this observation is unknown.

\section{Conclusions}

Experiments are conducted in an expansion tube facility to visualize bow shock shapes and measure heat flux over blunt bodies in a hypervelocity carbon dioxide flow. The blunt bodies of interest are spheres of varying diameters and a scaled version of the MSL aeroshell. This study was motivated by previous experiments at the CUBRC hypervelocity facilities that found that substantially different shock standoff distances were measured in different impulse facilities. One contributing factor is that the freestream carbon dioxide thermochemistry depends on the means by which the flow is accelerated to high velocities. To address this question and provide complementary results to those from CUBRC, we carry out the present experiments in the HET. Experimental shock layer shapes for different geometries, including spheres and the MSL forebody, are compared with simulations using the University of Minnesota solver, US3D, which incorporates detailed $\mathrm{CO}_{2}$ thermochemical modeling.

A test condition, labeled RC5, was selected by matching the stagnation enthalpy $(5.63 \mathrm{MJ} / \mathrm{kg}$ ) with a CUBRC test condition. Spheres with varying diameters were chosen as benchmark models for which shock standoff distances could be compared with existing data and theory. Excellent agreement was obtained between the simulation and the experiment for different diameters. Sphere stagnation point heat transfer measurements were in good agreement with semiempirical fits and noncatalytic numerical results.

The scaled MSL model was next tested in this flowfield. Shock shapes were visualized and heat transfer measurements were made at three different angles of attack: 0, 11, and $16 \mathrm{deg}$. Excellent agreement in the shock shapes between the simulations and the experiments was obtained at angles of attack of 11 and $16 \mathrm{deg}$. The present experiments are also in very good agreement with the CUBRC 
expansion tunnel data at a 0 deg of attack, implying the stagnation enthalpy and velocity are reasonable first-order matching parameters for these measurements in different expansion tube facilities. The results confirm facility independence for the same type of flow acceleration. The heat transfer data follow the general trends observed in previous experiments. Peak heating shifted to the windward side with a nonzero angle of attack. Windward-side heat transfer values appear quite insensitive to angle of attack, while the leeward-side values decrease appreciably with increasing angle of attack. In general, accounting for the experimental uncertainty, the data fall within the bounds of the two noncatalytic and supercatalytic numerical solutions.

\section{Acknowledgments}

For thermocouple implementation and design advice, the authors thank Hans Hornung, Simon Sanderson, Jean-Paul Davis, Bahram Valiferdowski, Ivett Leyva, Eric Marineau, and Adam Rasheed. For coordination with the Calspan University of Buffalo Research Center and the expansion tube gas dynamic discussion, the authors would like to thank Aaron Dufrene for his valuable input.

\section{References}

[1] Holden, M. S., Wadhams, T. P., MacLean, M., and Mundy, E., "Experimental Studies in LENS I and X to Evaluate Real Gas Effects on Hypervelocity Vehicle Performance," 45th AIAA Aerospace Sciences Meeting and Exhibit, AIAA Paper 2007-204, 2007.

[2] MacLean, M., and Holden, M. S., "Numerical Assessment of Data in Catalytic and Transitional Flows for Martian Entry," 9th AIAA/ASME Joint Thermophysics and Heat Transfer Conference, AIAA Paper 20062940, 2006.

[3] Stewart, D. A., and Chen, Y. K., "Hypersonic Convective Heat Transfer over 140-deg Blunt Cones in Different Gases," Journal of Spacecraft and Rockets, Vol. 31, No. 5, 1994, pp. 735-743. doi: $10.2514 / 3.26506$

[4] Wen, C. Y., and Hornung, H. G., "Non-Equilibrium Dissociating Flow over Spheres," Journal of Fluid Mechanics, Vol. 299, 1995, pp. 389405 .

doi:10.1017/S0022112095003545

[5] Netterfield, M. P., Mazoue, F., Marraffa, L., Kastell, D., and Eitelberg, G., "Experiments and Computations on a Blunt Body in High Enthalpy $\mathrm{CO}_{2}$," 31 st AIAA Thermophysics and Heat Transfer Conference, AIAA Paper 1996-1804, 1996.

[6] Hollis, B. R., and Perkins, J. N., "High-Enthalpy and Perfect-Gas Heating Measurements on a Blunt Cone," Journal of Spacecraft and Rockets, Vol. 33, No. 5, 1996, pp. 628-634. doi: $10.2514 / 3.26812$

[7] Hollis, B. R., and Perkins, J. N., "High-Enthalpy Aerothermodynamics of a Mars Entry Vehicle Part 1: Experimental Results," Journal of Spacecraft and Rockets, Vol. 34, No. 4, 1997, pp. 449-456. doi: $10.2514 / 2.3257$

[8] Wright, M. J., Olejniczak, J., Brown, J. L., Hornung, H. G., and Edquist, K. T., "Computational Modeling of T5 Laminar and Turbulent Heating Data on Blunt Cones, Part 2: Mars Applications," 43rd AIAA Aerospace Sciences Meeting and Exhibit, AIAA Paper 2005-177, 2005.

[9] Wright, M. J., Tang, C. Y., Edquist, K. T., Hollis, B. R., Krassa, P., and Campbell, C. A., "A Review of Aerothermal Modeling for Mars Entry Missions," 48th AIAA Aerospace Sciences Meeting and Exhibit, AIAA Paper 2010-0443, 2010.

[10] Holden, M. S., and MacLean, M., "Catalytic Effects on Heat Transfer Measurements for Aerothermal Studies with $\mathrm{CO}_{2}$," 44th AIAA Aerospace Sciences Meeting and Exhibit, AIAA Paper 2006-0182, 2006.

[11] Marschall, J., Copeland, R. A., Hwang, H. H., and Wright, M. J., "Surface Catalysis Experiments on Metal Surfaces in Oxygen and Carbon Monoxide Mixtures," 44th AIAA Aerospace Sciences Meeting and Exhibit, AIAA Paper 2006-0181, 2006.

[12] Mirels, H., "Shock Tube Test Time Limitation Due to Turbulent-Wall Boundary Layer," AIAA Journal, Vol. 2, No. 1, 1964, pp. 84-93. doi: $10.2514 / 3.2218$

[13] Mirels, H., "Test Time in Low-Pressure Shock Tubes," Physics of Fluids, Vol. 6, No. 9, 1963, pp. 1201-1214. doi: $10.1063 / 1.1706887$
[14] Mirels, H., "Laminar Boundary Layer behind Shock advancing into Stationary Fluid," NACA TN 3401, 1955.

[15] Mirels, H., "Boundary Layer Behind Shock or Thin Expansion Wave Moving into Stationary Fluid," NACA TN 3712, 1956.

[16] MacLean, M., Candler, G. V., and Holden, M. S., "Numerical Evaluation of Flow Conditions in the LENS Reflected Shock-Tunnel Facilities," 43rd AIAA Aerospace Sciences Meeting and Exhibit, AIAA Paper 2005-0903, 2005.

[17] Nompelis, I., Candler, G. V., and Holden, M. S., "Effect of Vibrational Nonequilibrium on Hypersonic Double-Cone Experiments," AIAA Journal, Vol. 41, No. 11, 2003, pp. 2162-2169. doi: $10.2514 / 2.6834$

[18] Park, C., "Thermochemical Relaxation in Shock Tunnels," Journal of Thermophysics and Heat Transfer, Vol. 20, No. 4, 2006, pp. 689-698. doi:10.2514/1.22719

[19] Neely, A. J., and Morgan, R. G., "The Superorbital Expansion Tube Concept, Experiment and Analysis," The Aeronautical Journal, Vol. 98, No. 973, 1994, pp. 97-105.

[20] Wegener, M., Sutcliffe, M., Morgan, R., McIntyre, T., and RubinszteinDunlop, H., "Diagnostics of a Range of Highly Superorbital Carbon Dioxide Flows," 39th AIAA Aerospace Sciences Meeting and Exhibit, AIAA Paper 2001-0304, 2001.

[21] Sasoh, A., Ohnishi, Y., Ramjuan, D., Takayama, K., and Otsu, H., "Effective Test Time Evaluation in High-Enthalpy Expansion Tube," AIAA Journal, Vol. 39, No. 11, 2001, pp. 2141-2147. doi: $10.2514 / 2.1210$

[22] Mizuno, H., Sawada, K., and Sasoh, A., "Numerical Analysis of Carbon Dioxide Flowfield in Expansion-Tube," 8th AIAA/ASM Joint Thermophysics and Heat Transfer Conference, AIAA Paper 20023221, 2002.

[23] Nompelis, I., Drayna, T. W., and Candler, G. V., "Development of a Hybrid Unstructured Implicit Solver for the Simulation of Reacting Flows Over Complex Geometries," 34th AIAA Fluid Dynamics Conference, AIAA Paper 2004-2227, 2004.

[24] Dufrene, A., Sharma, M., and Austin, J. M., "Design and Characterization of a Hypervelocity Expansion Tube Facility,' Journal of Propulsion and Power, Vol. 23, No. 6, 2007, pp. 1185-1193. doi: $10.2514 / 1.30349$

[25] McGilvray, M., Austin, J. M., Sharma, M., Jacobs, P. A., and Morgan, R. G., "Diagnostic Modelling of an Expansion Tube Operating Condition," Shock Waves, Vol. 19, No. 1, 2009, pp. 59-66. doi:10.1007/s00193-009-0187-9

[26] Hollis, B. R., Leichy, D. S., Wright, M. J., Holden, M. S., Wadhams, T. P., MacLean, M., and Dyakonov, A., "Transition Onset and Turbulent Heating Measurements for the Mars Science Laboratory Entry Vehicle," 43rd AIAA Aerospace Sciences Meeting and Exhibit, AIAA Paper 2005-1437, 2005.

[27] Sanderson, S. R., "Shock Wave Interaction in Hypervelocity Flow," Ph.D. Thesis, California Inst. of Technology, Pasadena, CA, 1995.

[28] Davis, J.-P., "High-Enthalpy Shock/Boundary-Layer Interaction on a Double Wedge," Ph.D. Thesis, California Inst. of Technology, Pasadena, CA, 1999.

[29] Rasheed, A., "Passive Hypervelocity Boundary Layer Control Using an Ultrasonically Absorptive Surface," Ph.D. Thesis, California Inst. of Technology, Pasadena, CA, 2001.

[30] Croarkin, M. C., Guthrie, W. F., Burns, G. E., Kaeser, M., and Strouse, G. F., "Temperature-Electromotive Force Reference Function and Tables for the Letter-Designated Thermocouple Types Based on the ITS-90," National Inst. of Standard Technologies, Monograph 175, 1993.

[31] Flaherty, W., and Austin, J. M., "Comparative Surface Heat Transfer Measurements in Hypervelocity Flow," 48th AIAA Aerospace Sciences Meeting and Exhibit, AIAA Paper 2010-0671, 2010.

[32] Doraiswamy, S., Kelley, J. D., and Candler, G. V., "Vibrational Modeling of $\mathrm{CO}_{2}$ in High Enthalpy Nozzle Flows," Journal of Thermophysics and Heat Transfer, Vol. 24, No. 1, 2010, pp. 9-17. doi:10.2514/1.43280

[33] Macrossan, M. N., "Hypervelocity Flow of Dissociating Nitrogen Downstream of a Blunt Nose," Journal of Fluid Mechanics, Vol. 217, 1990, pp. 167-202. doi:10.1017/S0022112090000672

[34] Sharma, M., Austin, J. M., Glumac, N. G., and Massa, L., "NO and OH Spectroscopic Vibrational Temperature Measurements in a Post-Shock Relaxation Region," AIAA Journal Vol. 48, No. 7, 2010, pp. 14341443. doi: $10.2514 / 1.50867$

[35] Paull, A., and Stalker, R. J., "Test Flow Disturbances in an Expansion Tube," Journal of Fluid Mechanics, Vol. 245, 1992, pp. 493-521. doi:10.1017/S0022112092000569 
[36] Lick, W., "Inviscid Flow of a Reacting Mixture of Gases Around a Blunt Body," Journal of Fluid Mechanics, Vol. 7, No. 1, 1960, pp. 128-144. doi:10.1017/S0022112060000086

[37] Hall, J. G., Eschendoeder, A. Q., and Marrone, P. V., "Blunt-Nose Inviscid Airflows with Coupled Nonequilibrium Processes," Journal of the Aerospace Sciences, Vol. 29, No. 9, 1962, pp. 1038-1051.

[38] Hornung, H. G., "Non-Equilibrium Dissociating Nitrogen Flows over Spheres and Circular Cylinders," Journal of Fluid Mechanics, Vol. 53, No. 1, 1972, pp. 149-176. doi:10.1017/S0022112072000084

[39] Inger, G. R., Higgins, C., and Morgan, R., "Shock Standoff on Hypersonic Blunt Bodies in Nonequilibrium Gas Flows," Journal of Thermophysics and Heat Transfer, Vol. 16, No. 2, 2002, pp. 245250.doi:10.2514/2.6674

[40] Belouaggadia, N., Olivier, H., and Brun, R., "Numerical and Theoretical Study of the Shock Stand-Off Distance in Non-Equilibrium Flows," Journal of Fluid Mechanics, Vol. 607, 2008, pp. 167-197. doi:10.1017/S0022112008001973

[41] Olivier, H., "A Theoretical Model for the Shock Stand-Off Distance in Frozen and Equilibrium Flow," Journal of Fluid Mechanics, Vol. 413, 2000, pp. 345-353. doi:10.1017/S0022112000008703

[42] McGilvray, M., Austin, J. M., Sharma, M., Jacobs, P. A., and Morgan, R. G., "Diagnostic Modelling of an Expansion Tube Operating
Condition for a Hypersonic Shear Layer Experiment," Proceedings of the 16th Australasian Fluid Mechanics Conference, Univ. of Queensland, Brisbane, Australia, 2007, pp. 385-393.

[43] Wegener, P. P., and Buzyna, G., "Experiments on Shock Stand-Off Distance in Non-Equilibrium Flow," Journal of Fluid Mechanics, Vol. 37, No. 2, 1969, pp. 325-335. doi:10.1017/S0022112069000577

[44] Wen, C., "Hypervelocity Flow over Spheres," Ph.D. Thesis, California Inst. of Technology, Pasadena, CA, 1994

[45] Hollis, B. R., and Perkins, J. N., "High-Enthalpy Aerothermodynamics of a Mars Entry Vehicle Part 1: Computational Results," Journal of Spacecraft and Rockets, Vol. 34, No. 4, 1997, pp. 457-463. doi: $10.2514 / 2.3258$

[46] Holden, M. S., Wadhams, T. P., Smolinski, G. J., MacLean, M., Harvey, J. K., and Walker, B. J., "Experimental and Numerical Studies on Hypersonic Vehicle Performance in the LENS Shock and Expansion Tunnels," 44th AIAA Aerospace Sciences Meeting and Exhibit, AIAA Paper 2006-0125, 2006.

[47] Sutton, K., and Graves, A. R., "A General Stagnation-Point ConvectiveHeating Equation for Arbitrary Gas Mixtures," NASA, TR R-386, 1971.

[48] Fay, J. A., and Riddell, F. R., "Theory of Stagnation Point Heat Transfer in Dissociated Air," Journal of the Aeronautical Sciences, Vol. 25, No. 2, 1958, pp. 73-85. 